\title{
Grassmann's Mathematical Epistemology and Generalization of Vector Spaces
}

\author{
그라스만의 수학 인식과 벡터공간의 일반화
}

LEE Hee Jung* 이희정 SHIN Kyunghee 신경희

\begin{abstract}
Hermann Grassmann classified mathematics and extended the dimension of vector spaces by using dialectics of contrasts. In this paper, we investigate his mathematical idea and its background, and the process of the classification of mathematics. He made a synthetic concept of mathematics based on his idea of 'equal' and 'inequal', 'discrete' and 'indiscrete' mathematics. Also, he showed a creation of new mathematics and a process of generalization using a dialectic of contrast of 'special' and 'general', 'real' and 'formal'. In addition, we examine his unique development in using 'real' and 'formal' in a process of generalization of basis and dimension of a vector space. This research on Grassmann will give meaningful suggestion to an effective teaching and learning of linear algebra.
\end{abstract}

Keywords: Grassmann, contrast, dialectics, real and formal, vector space, basis, dimension, generalization; 그라스만, 대비, 변증법, 실제와 형식, 벡터공간, 기저, 차원, 일반화.

MSC: 01A55, 01A73 ZDM: A35

\section{1 서론}

벡터공간의 내용과 진술 방법은 가설 연역적이고 공리적 접근으로 이루어져 있다. 이 러한 접근 방법은 오랜 발전 과정이 생략된 채로 전개되어 있어서 이해를 어렵게 한다. 그러나 개념 생성의 근원과 발전과정을 보여 주고 있는 벡터공간의 역사에 대한 연구는 소박하고 직관적인 상태에서 점진적인 형식화 단계를 거쳐 마침내 연역적 형식체계에 이른 과정을 보여준다. 이에 본고에서는 벡터공간 개념이 발생했던 시대적 상황을 살펴 보고 발전과정의 여러 단계에서 중심적 역할을 한 그라스만(Grassmann 1809-1877)의

*Corresponding Author.

본 논문은 강남대학교 2012년도 교내학술연구비를 지원받았음.

LEE Hee Jung: Dept. of Applied Math., Kangnam Univ. E-mail: hjlee@kangnam.ac.kr SHIN Kyunghee: Graduate School of Edu., Ajou Univ. E-mail: shinmat@ajou.ac.kr Receiveded on Apr. 5, 2013, revised on Apr. 27, 2013, accepted on May 27, 2013. 
수학에 관하여 연구하려 한다.

벡터해석학이 시작된 것은 1831 년 이후이다. 이 시기는 복소수를 기하학적으로 나타 내는 방법이 발견되고 라이프니쯔의 위치기하의 연구, 그리고 힘이나 속도를 평행사변 형으로 표기하는 아이디어 등이 등장한 때로 이러한 수학사적인 사건들이 벡터해석학이 시작되는 계기를 만들었다[1, 2]. 벡터공간의 개념을 처음 소개한 사람은 1844 년 독일 수학자 그라스만이다. 하지만 불행하게도 그의 수학은 너무 어려워 관심을 받지 못했고 페아노는 1888 년에 발행된 자신의 책 Calcolo Geometrico에서 그라스만의 연구를 전 하면서 현대적 의미의 벡터공간에 대한 공리들을 정리하였다. 하지만 이 역시 관심을 받지 못하다가 1918년 바일 (Weyl)이 아인슈타인의 상대성 이론을 소개하는 책 Space, Time, Matter에서 반복하여 사용한 이후 대중화되기 시작하였다[9]. 그라스만의 업적에 대한 분석은 수학자와 역사가들에게는 꼭 필요하다. 그라스만의 수학에 대한 연구는 19 세기 기하 위주의 수학을 대수로, 산술대수에서 구조를 갖는 추상대수로 옮겨가는 가교 역할을 하였다. 19 세기 후반 대수와 기하를 연결하는 독창적인 인식론적 접근을 했고 이후 반세기 만에 다양한 방법으로 재발견하였다. 그라스만의 관점은 독창적이었고 그의 저서 《확장론》은 순수수학의 확장 및 일반화 과정의 통찰을 보여준다.

본고에서는 먼저 그라스만의 《확장론》을 중심으로 벡터공간 발생의 시대적 배경을 살펴보고 3장에서 아버지 유스투스 그라스만으로부터 받은 수학의 영향력을 알아본다. 이어 4장에서는 벡터공간의 생성 과정과 수학의 확장에 대한 그라스만의 인식론적 접 근과 이 과정에서 대학 때의 스승 슐라이어마허에게서 받은 영향력에 대해서 분석한다. 그리고 5장에서 그라스만의 대비와 변증법적 방법을 사용하여 기저와 차원의 동일 개념 에 대해서 연구한다. 결론적으로 그라스만에 관한 연구는 선형대수 전 과정의 효과적인 교수학습을 위한 시발점이 되고 직관적 사고의 중요성과 창의적 사고의 관점을 제공하는 계기가 될 것이다.

\section{2 수학사적 배경}

19 세기 수학사는 차원의 일반화를 촉진시킬 수 있는 커다란 사건들이 있었다. 하나는 비유클리드 기하의 발견으로 기하 전반에 대한 기본을 재정립할 수밖에 없는 분위기가 지배적이었다. 사영기하, 대수기하 등도 기존의 전통적인 기하 영역을 차지하는 일대 대변혁의 시기를 맞고 있었다. 또 다른 사건은 해밀턴의 사원수의 발견이다. 이는 피콕 이 주장했던 형식 불역의 원리를 무효화시킬 정도였다[3]. 피콕은 대수학에 구조가 존 재한다는 것을 최초로 인식한 수학자로 양의 정수에 덧셈과 곱셈이라는 두 연산이 있고 교환법칙, 결합법칙, 배분법칙이 성립하는 것을 통상적으로 받아들이면서 이 성질들을 양의 정수 이외의 다른 원소의 집합에도 적용할 수 있을 것이라는 생각을 하게 된다. 
피콕은 대수를 산술대수(Arithmetic Algebra)과 기호대수(Symbolic Algebra)로 나누 고 양의 십진수로 전개할 수 있는 이전의 산술대수의 성질을 대상과 기호의 확장을 전 제한 기호대수로 일반화하였다. 여기에 이전의 성질이 확장된 대상에도 성립되는 형식 불역의 원리를 적용하였다[5]. 이 두 사건은 차원의 문제를 행렬식과 행렬 이론과 더불 어 임의의 차원으로의 확장으로 이끄는 계기가 되었다. $n$ 성분을 갖는 원소들의 연산과 행렬 연구의 기하적 접근은 선형성 이론에 직관적인 아이디어를 제공하였다. 행렬식의 사용으로 여러 이론들이 통합된 것을 시작으로 3차원 이상의 차원의 연구는 여러 선형 문제들을 결합시키는 결과를 가져왔다. 도리에[3, 4]는 기하 안팎으로 선형성의 통합을 이루게 한 이러한 과정이 벡터공간 이론의 발전에 아주 중요한 단계임을 강조하고 있다. 라그랑주와 가우스의 연구는 이러한 시대적 상황의 연장선상에 있었고 그라스만은 이 분야의 대표적인 수학자였다.

1880 년까지 선형대수의 기본적인 수학적 결과들은 대부분 정립되어 있었지만 벡터 공간은 예외였다. 일찍이 양과 방향을 갖는 벡터는 물리학에서 시작되어 17 세기 말에 정립되었고 주어진 두 벡터의 합은 두 벡터를 변으로 하는 평행사변형의 제 4 의 꼭짓점 으로 표현되었다. 복소수의 기하적 표현에서 시작된 벡터의 수학적 개념은 18 세기 후반 에서 19세기 전반에 걸쳐 여러 수학자들에 의하여 독립적으로 도입되었다. 1797년 베젤 (Wessel)을 시작으로 1831년 가우스 등은 복소수를 평면 위에 점과 방향을 갖는 선분으 로 나타내었고 1835 년 해밀턴은 복소수를 대수적으로 정의하였다. 실수의 순서쌍으로 복소수를 대수적으로 표현하고 실수들의 연산과 똑같이 순서쌍끼리 덧셈을 하고 상수를 곱하였다. 해밀턴은 연산의 닫힘성(closure)과 교환, 결합, 역원 등에 관해 논하였다.

해밀턴은 차원을 확장하는 중요한 아이디어를 소개하였는데 $i, j$ 와 $k$ 를 기본 단위로 하고 실수를 계수로 하는 $a i+b j+c k$ 가 그것이다. 이는 3차원 유클리드 공간의 대수적 표현인 것이다. 여기서 해밀턴은 이들 대상을 '벡터'로 소개하고 있다. 이후 차원을 하 나 늘린 사원수를 1843 년 도입하고 근 20 여년을 이 연구에 몰두하여 사원수 관련 논문을 150 여 편을 발표할 정도로 왕성한 연구를 하였지만 실제 활용된 경우는 드물었다. 1853 년에 발간된 해밀턴의 저서 《사원수 강의 Lecture on Quaternions》는 737쪽의 본문에 별도의 철학적인 서문이 무려 64쪽에 달했다. 루이스[6]는 그라스만의 《확장론》을 탐 독한 것으로 알려진 해밀턴이 그라스만이 전개한 개념의 일반화 단계에서 나타나는 '두 번째 단계', '세 번째 단계', '각 단계에서의 동치류' 등에 관심이 많았고 이들 연구가 사원수 발견에 어느 정도 영향을 끼쳤을 것이라고 주장하고 있다. 이 개념들은 집합들 사이에 구조를 비교하는 수학의 추상화에 관련된 힌트가 될 수 있기 때문이다. 또한 문 맥에서 사용된 언어도 비슷한 양상을 보이고 있다. 그즈음 케일리도 논문 $<n$ 차원 해 석기하 Chapters of analytic geometry of $n$-dimensions $>$ 에서 차원에 관련한 내용을 
독립적으로 발표하였다.

하지만 차원의 확장에 관련하여 《확장론》에서 보인 그라스만의 아이디어는 단연 독보 적이었고 시대를 앞서가는 것이었다. 그의 의도는 임의의 차원을 넘나드는 자유로운 공 간을 구성하는 것이었다. 그의 책에는 $n$ 차원 벡터공간, 부분공간, 생성집합, 일차독립, 기저, 차원, 선형변환 등 거의 대부분의 선형대수의 기본적인 개념들이 포함되어 있다. 벡터공간은 실수와 기본벡터 단위들의 일차 결합 $\Sigma a_{i} e_{i}(i=1,2, \cdots, n)$ 으로 정의하고 있고 이들의 연산과 성질 등이 총 망라되어 있다.

1844년 그라스만은 저서 《확장론, Die Lineale Ausdehnungslehre》을 출판하였다. 그는 이 책을 세상에 내놓으면서 자신의 수학이 기하라는 영역에 매이지 않는 새로운 수학의 한 분야가 되기를 희망하였다. 그라스만은 새로운 아이디어를 도입할 때 철학적 관점으로 시작하고 이론을 전개한 후 말미에 가서야 기하와 역학이 관련된 실제적인 문 제를 다루었다. '정역학, 역학, 자기학, 결정학(crystallography)등 수학 각 분야의 응용 을 설명하는 수학의 새로운 분야' 라는 부제가 달린 이 책은 공간을 다루는 과학으로서의 기하와 '추상적인 대상' ${ }^{1)}$ 을 다루는 순수수학을 명료하게 구별하였다. 하지만 거의 대부 분의 수학자들은 그를 비난하였는데 개념이 분명하지 않고 철학적인 서문이 아주 길어서 본문에 들어가기도 전에 책을 덮어버릴 수밖에 없다는 이유에서였다[4, 6]. 기존의 기하를 넘는 광범위한 스케일과 새로운 수학에 대한 낯선 전개방식은 책 내용에 대한 이해를 어렵게 했다[7]. 수학이론을 도입하면서 필요한 여러 개의 정의를 나열하면서 기존의 수학자들에 게도 낮선 독일어로 새로운 용어를 정의하였다. 대학에서 철학을 공부했고 언어학자로서도 뛰어난 능력을 보였던 그에게 이러한 전개 방식이 나름 의미가 있었겠지만 그 책을 접하는 수학자들에게는 오히려 커다란 장애가 되었다. 때문에 그의 책을 자세히 읽은 사람이 극소 수에 불과하였다. 1862 년 그라스만은 수학자들의 구미에 맞게 책의 형식을 바꾸어 개정판 을 내놓았다. 철학적 관점을 배제하고 정의-정리-증명으로 이어지는 유클리드 전개방법과 같은, 보다 수학내용에 충실한 개정판이었지만 그 역시 자신의 아이디어를 세상에 알리는 데에는 실패하였다[3].

그라스만의 천재성을 알아보고 수학이나 물리학에 그의 이론이 깊숙이 관여되어 있다는 사실을 후세 사람들이 알아본 것은 그의 사후에 이루어졌다. 1920년 경 카르당(Cartan)은 다중 선형대수 와 미분기하를 정립하는 과정에 그라스만의 다양체 개념이 중심 역할을 하고 있다는 사실을 알았다. 1994년 그라스만의 《확장론》 출판 150주년을 기념하여 폴란드의 뤼겐 ${ }^{2)}$ 에서 수학자, 자연과학자, 철학자, 교사 그리고 음악학자로서의 그라스만을 기억하는

1) 그라스만은 이를 'extensive magnitudes' 로 표현하였다. 차원의 제한을 두지 않는 추상적 대상을 다루는 기하를 의미한다[7].

2) 그라스만이 거의 생전을 보냈던 독일의 스테틴 (Stettin)은 현재 폴란드의 도시 Sczcezin이며 뤼겐은 이 도시 가까이 있는 섬이다. 
자리가 마련되었다. 그가 만든 새로운 수학과 독창적인 표현 방법 등이 후세에 끼친 내용 그리고 그 업적이 현재에도 여전히 중요한 영향력을 갖고 있다는 것을 확인하는 자리였다.

\section{3 아버지 유스투스 그라스만의 영향}

그라스만은 신학과 철학을 공부했고 수학은 중등학교 수학교사였던 아버지의 영향을 받으 면서 혼자 공부하였다. 수학에 관한 한 정규수업을 듣지 않은 그라스만의 수학을 이해하는 데는 영향을 가장 많이 주었던 아버지 그라스만의 수학을 살펴보지 않을 수 없다. 아버지 유스투스 그라스만(Justus Grassmann)은 신학과 수학을 공부했고 수학교사가 된 이후 46년을 재직하면서 기하해석학을 연구하고 교과서와 논문도 여러 편 출판하였다. 아버지 그라스만을 연구해야하는 이유를 라두[9] 는 다음 두 가지에서 찾고 있다. 하나는 19세기 전반 수학의 기초를 누구보다 앞서 확립한 사실과 또 하나의 이유는 아들 그라스만에 끼친 수학적 영향을 들고 있다. 유스투스 그라스만은 피히테 (Fichte), 셸링 (Schelling), 헤겔 (Hegel) 등 철학계의 거성들이 있는 예나(Yena) 대학 영향 하에 있는 할레 (Halle)에서 신 학을 공부하였다. 이들은 모두 보편타당한 인식은 어떻게 가능한가에 대한 질문에 합리론과 경험론의 종합으로 명쾌한 이성비판철학을 확립한 칸트(Kant)의 인식론에 깊게 영향을 받 은 철학자들이었다. 칸트는 이성비판에 분석판단과 종합판단을 구별하고 분석판단은 주어 개념에 술어개념이 포함되어 있는 판단이며, 종합판단은 주어 개념에 술어개념이 포함되어 있지 않은 판단이라 하였다. 칸트 자신은 보편타당한 인식은 어떻게 가능한가라는 질문은 선천적 종합판단은 어떻게 가능한가라는 질문과 동일시하였다. 칸트는 선천적 종합판단의 예로서 수학적인 판단을 제시한다. $2+5$ 는 의심할 바 없이 7 이라는 점에서 선천적이며, $2+5$ 의 개념에는 7 이라는 개념이 들어 있지 않고 또한 경험적인 계산을 필요로 한다는 점에서 종 합판단이다. 이러한 철학적 인식론은 당시 시대적 분위기와 맞물리며 유스투스 그라스만이 수학을 구성하는데 기본적인 바탕이 되었으리라는 것을 쉽게 짐작할 수 있다. 그는 수학을 산술, 순열-조합론, 기하 등 세 분야로 나누어 설명하고, 자신의 기하교과서를 전개하고, 조합기하 분야인 결정론 ${ }^{3)}$ 을 연구하면서 위에서 언급한 수학지식 구성의 과정을 기본적으로 따랐다. 이러한 지식구성의 철학적인 인식론 바탕위에 또 하나의 변화가 있었다. 유럽전역 에 퍼져있는 학문과 교육 혁명이 진행되고 있던 시대적 상황에 맞춰 유스투스 그라스만도 그 흐름의 분위기에 동참할 수밖에 없었다. 당시 독일은 흠볼트 (Humboldt) 교육개혁이 진행되고 있었다. 기존의 언어학과 신학 대신에 과학철학에 근거한 교육을 강조했고 수학도 기본 계산 중심의 실제적인 수학보다는 고급계산법과 사영기하 등 이론적이고 순수수학을 지향하였다. 위에서 아래(up-down)로 진행되었던 흠볼트 개혁은 실제 현장에서의 교사

3) 유스투스 그라스만은 자연과학과 수학 사이의 새로운 학문을 combinatorial geometry라고 명명하였다. 
교육이 미비한 상태였으므로 여러 어려움이 있었지만 적어도 기성수학의 전달만이 교육은 아니라는 교육적 가이드라인을 분명하게 심어주는 계기가 되었다. 이 가이드라인은 당시 급진적 구성주의자인 피히테 (Fichte) 의 영향을 받은 것으로 지식은 플라톤주의식의 완전한 것이 아니라 행동의 조작경험에 의하여 자유롭게 형성된 것이라고 주장하였다. 지식에 대한 이러한 개혁의 관점은 수학교육에도 지대한 영향을 미쳤다. 라두(2000)는 이러한 학문적 교육적 배경과 아버지 그라스만 수학의 영향으로 그라스만이 발전시킨 수학은 구성주의적 인 관점과 공리적인 관점이 적절히 배합되어 있다고 평가하고 있다.

\section{4 그라스만의 수학인식론}

그라스만의 수학 전개방식의 특징은 '대비 (contrast)' 를 이용한 것이다. 연속과 이산, 같음 (equal) 과 다름(different) 등이 그것이다. 이것은 사고 체계를 다음 그림과 같이 네 영역으 로 나누고 이를 기본으로 수학의 전개를 다루고 있다[6].

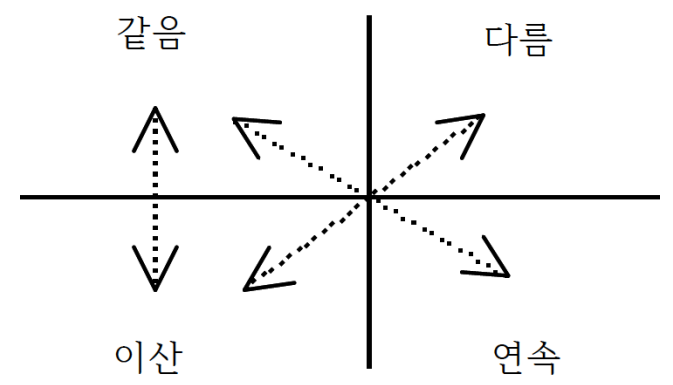

Figure 1. Thinking system of Grassmann; 그라스만의 사고체계

사실 이러한 지식을 구성하는 기본 가정은 그라스만의 아버지 유스투스 그라스만의 아이 디어를 그대로 이용한 것이다. 유스투스 그라스만은 수학에서 직관의 역할을 강조하였다. 직관을 외적직관과 내적직관 ${ }^{4}$ 으로 나누고 이 둘은 서로 독립적이어서 하나가 나머지 하나 를 제한할 수 없다고 주장하고 있다. 그는 수학을 정의하는데 몇 가지 필요한 조건을 내세 웠다. 첫번째로 수학의 일관성 (unity of mathematics)을 나타낼 수 있어야하고, 둘째는 논리적 사고와 대비되는 수학적 사고의 특성이 반영되며, 셋째, 수학의 자연스러운 분류와 그 분류가 단순히 형식적인 연역적 논리에 의한 것이 아닌 구체적이고 실제적인 것으로부터 구성되는 특별한 방법에 따라야할 것을 강조하였다. 마지막으로 이러한 순수수학을 응용할 수 있는 가능성을 제시할 수 있어야 함을 주장하고 있다[2, 7]. 유스투스 그라스만은 위에서 제시한 필요조건 등을 발달시켜 수학지식을 구성하는 양식을 두 가지로 분류하였다. 이를 외적종합(external synthesis) 과 내적종합(internal synthesis)으로 소개하였고 1827년

4) 외적직관을 '지각할 수 있는(sensible) 직관', 내적직관을 '지적 (intellectual) 직관' 이라고도 하였다. 
출판된 자신의 논문에 발표하였다. 여기서 외적종합은 수학적 종합으로, 내적종합은 논리적 종합으로 설명하고 있다[9]. 수학에 대한 기존의 존재론적이고 방법론적인 정의를 탈피한 그라스만의 아이디어는 외적종합과 내적종합의 차이를 드러나게 하였고 내용과 형상의 차이를 인식하게 하였다. 이러한 그의 접근은 '수학적 종합은 어떻게 작용하고 또한 논리적 종합은 어떻게 작용하는가, 그리고 각각은 서로에 어떤 기능을 하는가 등에 대한 여러가지 질문을 초래하였다. 여기서 유스투스 그라스만은 위 Figure 1에 있는 네 가지 기본 요소, '같음' 과 '다름', '이산' 과 '연속' 를 가정하고 이를 바탕으로 '수학적 종합' 의 개념을 만들 어 냈다. 그 중의 한 부분인 '같음으로서의 종합(synthesis as equal)' 은 '양 (magnitude)' 을 만들고 '다름으로서의 종합(synthesis as unequal)' 은 '조합(combination)' 을 생성한 다. 5) 그 결과 '양' 은 '산술 (arithmetics)' 을 '조합' 은 '순열 조합론' 을 탄생시켰다. 마찬 가지로 '이산에서의 종합' 은 '포괄적인 기호 종합 (extensive sign aggregates)' 을 '연속 에서의 종합' 은6) '내포적 기호 종합(intensive sign aggregates)' 을 각각 생성하였다. 이 과정은 수학을 정의하고 분류하는 그라스만의 독특한 접근 방법을 보여준다. 다음 표는 그가 분류해놓은 수학의 분야를 나타내고 있다.

\begin{tabular}{|c|c|c|}
\hline 수학적 분류 & 종합 유형 & 결과 유형 및 대상 \\
\hline 산 술 & 이산과 같음의 종합 & 포괄적인 양, 수 \\
\hline 순열조합론 & 이산과 다름의 종합 & 포괄적인 조합 \\
\hline 기 하 & 연속과 같음의 종합 & 내포적인 양, 연속적인 양 \\
\hline 네 번째 분야 & 연속과 다름의 종합 & 내포적인 조합 \\
\hline
\end{tabular}

Table 1. Mathematical Synthesis of Grassmass; 그라스만의 수학적 종합

대상 자체를 정의하는 것이 아니라 구체적인 대상에 대응하는 유형을 구성하는 특별한 방법에 의해 수학이 정의되고 수학의 각 분야를 나누고 있는 것이다. 하지만 그라스만은 이후 수학의 분야를 분류할 때 네 번째 수학적 분류인 연속과 다름의 종합은 제외시키고 위 세 경우 산술, 순열조합론, 기하만을 자신의 수학으로 분류하고 그 내용을 구체적으로 진술하고 있다.

여기서 수학을 정의하고 분류하며 수학명제를 구성하는데 자연스러움을 여러 번 강조하고 있다는 부분에 유의할 필요가 있다. 자연스럽다는 것은 지각 가능한 실체로부터 점진적인 형식화와 일반화를 의미한다. 그라스만은 수학을 정의하고 설명하는데 아버지 그라스만의 철학을 그대로 적용하고 있다. 수학지식 구조와 구성에 대한 아버지 그라스만 철학에 깊이

5) 예를 들어 같은 것(token)이 여러 개 주어졌다고 하자. 여기서 '같다' 는 것은 그들이 놓인 위치, 모양, 중요성 등의 차이는 무시함을 뜻한다. 이들은 $||,||||,, \ldots$ 등의 형태로 나타낼 수 있는데 이로부터 '이산적인 양' 을 생성한다. 또한 '같지 않은' 것들은 일련의 문자 'abcdefg' 로 표현할 수 있고 이는 '조합' 을 구성한다[9].

6) 몇 개의 점은 '이동' 에 의해 직선을 만들 수 있는데 이는 '연속에서의 종합' 유형이다[9]. 
영향을 받았음을 알 수 있다.

아들 그라스만은 수학의 한 분야로서의 확장이론을 전개하면서 위에서 언급한 대비를 사용하여 연속과 이산, 같음과 다름을 기본 축으로 사고과정을 전개하고 있다. 사고수단이 되는 각각은 '가정하기 (positing)' 와 '연결하기 (connecting)' 의 두 가지 행동을 통하여 나타난다. 수학의 실체인 '사고형상(thought-forms)' 은 같음과 다름에 의해 생성되는데 이것은 두 단계로 나타난다. 그 하나는 존재 자체로서의 단계, 그 다음은 그것과 동치인 것을 표현한 기호의 단계인데 그라스만은 이 각각을 '실제 (real)' 와 '형식 (formal)' 이라 불렀다[6]. 실제를 기호로 표현하고 다시 기호는 그 실제를 의미한다.

또한 그라스만은 연결 (connection) 과 분리 (separation) 의 대비를 사용하였다. 그가 책에서 사용한 예를 인용하면 항 (term) $)^{7)} a$ 와 $b$ 가 주어졌을 때 이 둘의 연결은 $(a \cap b)$ 가 될 수 있고 이는 처음 주어진 형상인 $a$ 와 $b$ 를 연결하여 새로운 형상인 $(a \cap b)$ 를 생성하고 있다. 이는 또다른 생성 과정을 거쳐 $((a \cap b) \cap c)$ 가 만들어진다. 기호 $\cap$ 는 그것이 가지고 있는 본래의 의미에 따라 상황에 따라 선택되어진다. 여기서 기호를 움직이거나 없애도 실제로 결과는 변함이 없으므로 $((a \cap b) \cap c)$ 는 $a \cap b \cap c$ 로 바꾸어 써도 된다. 마찬가지로 $(a \cap(b \cap c))$ 는 $a \cap b \cap c$ 와 결과적으로 같으므로 결합법칙 $(a \cap b) \cap c=a \cap(b \cap c)$ 이 성립함을 보이고 있다. 이것이 그가 보인 첫 증명인데 여기서 결합법칙이라는 용어는 사용하지 않았 지만 최소한의 기호만으로 거의 자신이 선택한 몇 개의 용어를 사용하여 언어로 풀어가는 증명 방법을 택하고 있다 $[3,4]$. 위와 같이 결합법칙은 세 원소를 다르게 연결하여 얻을 수 있는 두 형태를 같다고 간주할 수 있는 가능성을 형식화한 것이다. 그러므로 그라스만의 접근은 공리적 접근과는 다르고 다른 것들의 연결에 의해서 얻어지는 다양한 형태가 같음 또는 다름으로 간주될 수 있는 가능성들의 체계적인 결합에 의한 결과이다. 이러한 것들이 새로운 대상을 창조하는데 있어서 형식적인 과정을 지배하는 체계상의 규칙을 설립하는데 핵심적인 역할을 한다. 이렇게 더하고 빼는 변증법적 사고는 그라스만의 수학전개에서 반복하여 나타나고 있다. 이는 1827년부터 1830 년까지 베를린 대학의 철학과 신학 스승 이었던 슐라이어마허(Schleiermacher) 의 절대적인 영향을 받은 결과였다. 그는 다음과 같이 술회한 바 있다. '슐라이어마허의 강의를 처음 한두 학기 들었을 때는 거의 이해하지 못했다. 그럼에도 그로부터 받은 감동 때문에 나 자신 내부의 변화를 느낀 이후에는 열심히 노력하여 마지막 학기에는 그를 완전하게 이해할 수 있었다. 나의 기본 신념과 사고의 원 천은 슐라이어마허다.’[6] 당시에 언어학에 관심이 많았던 그라스만은 이때 처음으로 모든 과학은 슐라이어마허의 철학으로 설명될 수 있을 것이라는 인식을 하게 된 듯하다. 지식의 확실성을 제공할 수 있으리라는 믿음과 그 방법에 대하여 진지하게 고민했다. 그 즈음에

7) 그라스만은 연결(connection)을 설명하면서 'term', 'result', 'first term', 'second term' 등의 용어를 사용 하였다. 여기서 $a$ 는 first term, $b$ 는 second term으로, $(a \cap b)$ 는 그의 연결로 이루어진 result로 표현하고 있다[6]. 
그라스만은 슐라이어마허가 쓴 변증법에 관련된 여러 권의 책을 읽었고 1842 년에 드디어 스스로 수학에 관한 책8)을 쓰려고 마음을 먹게 된다. 당시 대부분의 철학자와 마찬가지로 슐라이어마허도 수학은 불변이고 내적으로 안정적인 학문이라고 여겼다. 제자에 의해 정리 된 강의록〈변증법〉에는 수학을 '양 (quantity) 의 과학' 으로 정의하고 내용은 주로 산술과 기하로 서술되어 있다. 이러한 제한된 정의에도 불구하고 수학의 중요성을 강조하면서 지 식에 대한 실제적인 사고는 변증과 수학이라고 하였다. 수학과 철학적 문맥에서 그라스만의 아이디어를 연구한 오뜨[8]는 그라스만이 수학의 정의와 아이디어 사이의 관련성을 어떻게 보고 있는가를 관찰하였다. 일찍이 라이프니쯔는 명목상의 정의가 아니라 확실한 가능성을 포함하는 실제적 정의가 필요하다고 하였고 그라스만은 여기에 개념적 구성과 지적 역학까 지 추가할 것을 요구하였다. 개념적 원소는 역사적인 자의식이 드러나는데 주어진 대상에 대한 수동적인 것이 아니라 주어진 경계를 뛰어넘는 소위 일탈이어야 함을 주장하였다. 1844 년 그라스만이 받아들인 표현법에는 정밀함과 즉시에 전체를 보는 가능성의 상반되 는 두 목적이 계속적으로 나타난다. 그는 또 다른 대비, 노출의 정밀함과, 직관과 기하와 유사한 것에 있어서의 구체화를 보여주고 있다. 이 대비는 계속되는 변증법의 과정에 대한 개념을 결정한다. 이러한 선택이 그의 작업에 구체적인 리듬을 준다. 몇몇 개념들은 정확한 정의보다는 다소 느리고 반복되는 과정에서부터의 다른 직관들로부터 나온다. 이러한 일 련의 과정은 다른 수학자들이 그라스만을 받아들이고 이해하는 것을 어렵게 했을 것이라고 짐작하는 부분이다.

후에 스피노자의 영향을 받아 지식을 형성하는 가장 좋은 방법으로 발견법 (heuristic) 을 주장하였는데 이는 일반적이고 특별한 원리를 동시에 줄 수 있는 방법이기 때문이라고 하였다. 지식을 형성하기 위하여 특별한 직관이 필요한데 이 발견법이 유용하게 작용한다는 것이다. 그라스만은 이러한 일반적이면서 특별한 대비를 과학의 엄밀한 전개에 이용하였다. 순수과학에서 유추를 사용하여 그의 응용인 기하를 설명하고 직관을 이용하여 기하를 정 리하였으며 마침내 응용학문으로서의 역학을 설명하였다. 슐라이어마허는 수학을 하려면 예언적인 직감이 필요함을 인지하기도 하였다. 이것이 직관이고 이 직관이 발견법으로 설명 될 수 있다. 그라스만 역시 이에 동의하면서 진리는 얻어진 결과들을 맹목적으로 결합하여 얻어지는 것이 아니고 어떠한 예감에 의해 발견되는 것이라 하였다. 처음에는 모호하고 단순해 보이지만 조직적인 과정을 거치면서 새로운 지식으로 탄생하게 된다는 것이다.

이러한 직관이 따르는 발견법은 그의 《확장론》제 1 장에서도 나타난다. 한 점을 움직여 직선을 만들 수 있고 같은 방법으로 직선을 움직이면 공간이 창조된다는 사실에서 유추적 사고를 동원하면 순수과학의 한 원소로부터 적당한 개념을 지닌 확장된 실체를 얻을 수 있

8) 1844 년 대작 《확장론》을 완성하게 된다. 
다고 하였다. 같은 변화에 의해 계속해서 만들어지는 원소들의 집합체를 동치류'라라 하였고 같은 방향과 같은 길이를 갖는 선분들은 같다고 하였다. 그러므로 이러한 동치류는 무수히 많은 선분으로 이루어지고 처음 주어진 구체적인(real) 양 ${ }^{10)}$ 에서 변화의 결과물인 동치류는 처음과는 별도(separation) 인 추상적인 산물인 것이다. 여기서 그라스만은 구체에서 추상 으로의 분리는 절대적인 분리가 아니라 구체에서 추상을, 다시 추상에서 구체를 상상할 수 있는 변증법적인 영향 아래 있음을 강조하였다. 또한 언제나 구체에서 추상으로의 변환만 있는 것이 아니라 때로는 추상이 선행할 수도 있음을 보였다.

\section{5 벡터공간의 일반화}

앞서 논의 하였듯이 그라스만의 수학 확장의 요체는 계속적인 변화를 통해 새로운 대상을 창조하는 것이다. 특별과 일반의 대비를 통한 생성과정은 대상들의 일반적인 접근이 어떻게 가능한지를 보여주고 있다.

이와 같은 아이디어는 그라스만으로 하여금 선형대수에 있어 매우 구체적인 연구를 가 능하게 하였다 그의 이론은 기하학적 직관에 기초할 뿐만 아니라 매우 형식적이다. 본 논 문에서는 도리에 (Dorier) 의 1995년과 2000년 논문의 내용을 중심으로 그라스만이 전개한 벡터공간의 차원의 일반화를 분석하고자 한다.

그라스만은 공간 ${ }^{11)}$ 개념의 일반화를 '변화(change)' ${ }^{12}$ 를 통하여 전개하고 있다. 처음 주어진 원소는 변화를 통하여 두 번째 단계의 공간을 만들고 여기에 기존과는 독립된 원소를 더하여 세 번째 공간을 생성할 수 있고 이 과정은 계속된다. 그라스만은 세 번째 단계인 3 차원 공간을 예로 들어 이를 구체적으로 설명하고 있다. 한 개의 점은 한 방향 혹은 반대 방향으로 변화를 통하여 직선을 만들고 또 다른 직선이 앞의 것과 결합되는 변화를 통하여 두 번째 단계인 평면이 생성된다. 결국 두 개의 직선으로 무수히 많은 방향을 가진 직선이 포함된 평면이 만들어진 것이다. 여기에 앞의 두 개와 독립된 방향을 가진 직선이 첨가되어 세 번째 단계인 3차원 공간이 생성되는 것이다. 여기서 독립된 방향을 가진 직선을 택하는 것을 그라스만은 변화의 중요한 성질로 강조하고 있다.

이러한 일련의 과정은 상당히 역동적이다. 즉 차원이 단계적으로 커지는 것이다. 여기서 변화가 핵심개념이 되는데 이는 시간과 동작의 조화로 마치 육체가 영혼에 가까이 있는

9) 그라스만은 이를 'a system of first step' 이라 불렀다.

10) 그라스만은 이를 'stretch' 라 하였고, 확장하려고 하는 처음 주어진 실체, 예를 들어 점이나 혹은 방향과 길이를 갖는 선분 등을 의미한다. 또한 'real' 은 항상 눈에 보이는 것뿐만 아니라 적당한 법칙에 의해 확장될 수 있는 형상 (thought form) 을 뜻한다.

11) 'system' 을 문맥의 이해를 위하여 '공간' 으로 나타내었다.

12) 수학을 확장하는 중요한 기본 개념이라고 진술한 그라스만은 이를 'change' 혹은 'rules of change' 로 표현했지만, Dorier는 'evolution' 으로, Lewis는 'motion' 으로 나타내었다. 자칫 일반 명사로 그 의미를 지나칠 수 있지만 본 논문에서는 '변화' 로 표현하고 문맥상 필요한 부분에는 '전개’ 로 나타내었다. 
만큼 우리에게 부착되어 있는 근본적인 직관에 근거하고 있다[3].

그라스만은 기저와 차원이 결국은 같은 개념이라고 주장한다. $n$ 번의 변화를 통하여 생성된 공간은 서로 다른 $n$ 개의 벡터가 분명한 순서로 열거되어 있다. 그라스만은 그들이 $n$ 보다 적은 어느 공간에도 속하지 않는다는 의미에서 그들을 독립이라고 말한다. 즉 일차 독립과 생성은 근본적으로 연관되어 있고 공간을 확장하는 순서는 자연스럽게 생각할 수 있는 차원의 이전 개념으로 보여진다. 먼저, 한 공간 위에 있는 벡터 ${ }^{13)}$ 들만을 고려한다. 여기서 그라스만은 ‘특별' 과 ‘일반' 의 대비를 사용하고 있다. 그 공간상에 있는 '특별' 한 벡터들은 그 다음 단계의 공간을 생성하여 '일반' 화를 꾀하는 원소로 사용된다. 이러한 목표 에 도달하기 위해서 그는 또 다른 대비, '실제' 와 '형식' 을 사용하는데 동일 공간상에 있지 않은 새로운 벡터들을 택하는 것이다. 이렇게 택한 새로운 벡터들의 첫 번째 유형은 기존의 벡터들의 합으로 표현된다. 그라스만은 같은 공간에 속한 벡터들의 합으로 시작해서 서로 다른 공간에 속한 벡터들의 합을 이어나감으로서 일반화의 목표를 달성하고 있다. 이같은 그의 전개는 기하학적 직관과 덧셈규칙 ${ }^{14)}$ 에 기초하고 있다. 또한 그라스만은 변화의 각 단계에 속해 있는 벡터들의 합이 결합법칙 ${ }^{15)}$ 이 성립한다는 것을 보였다. 두 벡터들의 합의 순서를 바꾸는 것은 근본적으로 변화의 순서를 바꾸는 것과 관계되는데 형식적인 변경은 이론의 실제적인 면을 고려해볼 때 아무런 영 향을 미치지 않으므로 결합법칙이 성립한다고 주장하고 있다.

$n$ 번째 공간은 $n$ 번의 기본적인 변화의 전개를 거쳐 생성되고 그 공간의 임의의 벡터 $p$ 는 $n$ 개의 벡터들의 합으로 나타낼 수 있다. 예를 들어 $n$ 번째 공간에 있는 두 개의 벡터 $p_{1}$ 과 $p_{2}$ 는 $p_{1}=a_{1}+a_{2}+a_{3}+\cdots+a_{n}$ 과 $p_{2}=b_{1}+b_{2}+b_{3}+\cdots+b_{n}$ 로 나타낼 수 있고 그 두 벡터의 합은 $p_{1}+p_{2}=\left(a_{1}+b_{1}\right)+\left(a_{2}+b_{2}\right)+\left(a_{3}+b_{3}\right)+\cdots+\left(a_{n}+b_{n}\right)$ 으로 표현되 는데 이것은 위에서 그라스만이 언급한 벡터들의 합의 교환과 결합에 대한 성질에 의해서 가능하다. 이보다 더 큰 공간을 생성하기 위해서는 그것이 만들어지는 기본적인 변화의 방법을 알아야만 한다. 이는 변화로부터 얻어진 공간 벡터들에 대한 독립성을 연구하는데 한걸음 나아가게 한다. 왜냐하면 $n$ 번째 공간은 $n$ 번의 변화를 거쳐 생성된 서로 독립인 벡터들에 의해서 생성되기 때문이다. 즉, 더 작은 벡터들로 만들어진 공간에는 포함되지 않기 때문이다.

위에서 공간이 만들어지는 각 단계는 생성자의 특별한 선택과 연관될 뿐만이 아니라 공간의 크기를 나타내는 특징을 지닌다. 이와 같이 각 단계에서 드러나는 독립성의 개념은 단지 근본적인 변화에만 관심이 있어서 실제로 그라스만이 제안한 단계의 일반화 과정 은 다소 애매한 부분이 있는 것은 사실이다. 그럼에도 불구하고 오늘날의 기저와 차원의

13)《확장론》에서는 벡터의 개념과 상응하는 용어로 전위(displacement)를 사용하였다.

14) 벡터의 덧셈 규칙 $\overrightarrow{A B}+\overrightarrow{B C}=\overrightarrow{A C}$ 를 의미한다.

15) 그라스만은 '결합법칙' 이라는 용어를 사용하지는 않았다. 
개념에 대한 몇몇 핵심적인 면을 이끌어 내고 있다. 기본적인 변화를 통하여 벡터 하나는 남은 것들과 독립인 다른 하나의 벡터로 바꿀 수 있다는 것을 보였는데 이것을 그라스만은 '교환 방법 (exchange method)' 이라 불렀다. 여기에서도 그라스만은 '실제' 와 '형식' 의 대비를 적용하고 있다. 덧셈의 교환을 형식적으로 사용하면서 그것이 갖는 의미는 실제적 이고 직관적이라고 설명한다. 만약 $p$ 가 $b, c, \cdots$ 와 독립이면 0 이 아닌 $a$ 를 사용하여 $p$ 를 $p=a+b+c+\cdots$ 로 표현할 수 있다. 이때 $a$ 에 속하는 임의의 벡터 $a_{1}$ 은 $p$ 에 속하는 벡터 $p_{1}$ 에 대응하고 $p_{1}=a_{1}+b_{1}+c_{1}+\cdots$ 와 같이 나타낼 수 있다. 여기서 그라스만이 언급한 교환 방법을 사용하면 $a_{1}=p_{1}-b_{1}-c_{1}-\cdots$ 가 된다. 이와 같이 $a$ 에 속한 어떤 벡터도 $p, b, c, \cdots$ 에 속한 벡터들의 합으로 대치될 수 있다. 전개의 순서를 다시 구성하는 것과 비슷한 벡터들로의 분할의 가능성이 $p$ 와 $a$ 의 교환을 확실하게 한다. 이와 같이 형식적인 측면과 실제적인 측면과의 변증법이 드러나는데 여기에서도 연역적인 형식의 엄밀함과 의미의 직관적인 파악의 대비를 사용하고 있음을 확인할 수 있다. 사실, 이것이 벡터공간의 임의의 기저에서 원소의 개수가 변하지 않는다는 것을 증명한 방법 중의 하나이다. 그것은 또한 내재적으로 기저와 차원의 개념의 의미를 포함하고 있는 것이다.

그럼에도 불구하고 그라스만은 이 결과로부터 모든 함축적인 문제를 분명하게 이끌 어내지는 않았다. 이를테면 이러한 교환 방법의 반복은 각 단계에 있어서 일정한 조건이 만족되어야 함에도 그라스만은 비록 그것을 함축적으로 인정하고 있었을 뿐 어디에서도 구체적으로 언급하지 않았다. 주어진 공간에서 대체되는 벡터들이 그 다음 단계의 새로운 벡터를 택할 때 독립성으로부터 연역된다는 사실을 정확히 언급하지 않은 것이다. 그럼에도 불구하고 그라스만의 교환방법은 벡터공간의 기저 개념에 중요한 의미를 갖는다.

\section{6 결론}

그라스만은 새로운 수학을 창조하려고 노력한 수학자였다. 그 결과가 기하나 역학 등 다른 과학 분야에 응용이 될 수 있다 하더라도 기존의 것과는 독립적인 새로운 이론의 학문을 추구하였다. 스승 슐라이어마허의 변증법 강의에 깊은 영향을 받아 수학을 새롭게 정립할 수 있다는 동기를 갖게 된 그라스만은 자신의 수학을 '확장론' 이라 하였다. 전개 방법도 이전의 수학적 추론의 법칙과는 독립적이어야 했으므로 새로운 정의와 기호가 필요했고 수학을 엄밀하게 표현할 수 있는 접근 방법이 필요했다. 그의 수학 확장의 요체는 계속적인 변화를 통해 새로운 대상을 창조하는 것이었다. 아버지 유스투스 그라스만의 수학을 물려 받은 그라스만은 수학을 정의하는 데 필요한 구성요소를 연구하였고 수학지식을 구성하는 독특한 양식으로 수학을 분류하였다. 수학에 대한 기존의 존재론적이고 방법론적인 정의 에서 그의 아이디어는 수학을 같음과 다름, 이산과 연속을 가정하고 이를 바탕으로 수학적 종합의 개념을 만들어 냈다. 또한 특별과 일반, 실제와 형식의 대비의 변증법적인 접근으로 
새로운 수학의 창조와 일반화의 과정을 보여주고 있다.

벡터공간 이론은 새로운 자료들의 구성에 있는 것이 아니라 기존의 문제를 바라보는 새로운 관점과 수학적 지식을 새롭게 조직하는 데 있다. 여기에서도 특별과 일반, 실제와 형식의 대비를 통한 벡터공간의 차원과 기저, 독립의 개념을 생성하고 이 과정을 통하여 대상들의 일반적인 접근이 어떻게 가능한지를 보여주고 있다.

그러나 대비에 바탕을 둔 그라스만 수학의 변증법적 접근은 당시의 수학자들에게는 상당 히 생소하였고 때로는 모호한 철학적 표현으로 수학 결과들을 유도해버리는 등 그의 수학은 극도의 비판의 대상이 되었다. 하지만 그라스만의 수학은 카르당(Cartan)의 대수, 카를로 로타(Carlo Rota)의 미분적분학에 영감을 주는 등 오히려 최근에 그의 수학이 새로운 관심 의 대상이 되고 있다.

결론적으로 그라스만에 관한 연구는 벡터공간을 비롯한 선형대수 전 과정의 효과적인 교수학습에 시사점을 제공하고 있다. 실제를 기반으로 하는 형식의 도입과 특별에서 시작 하는 일반화의 접근은 현재의 연역적인 전개에서 발생되는 어려움을 어느 정도 완화시킬 수 있다. 이 과정은 학습자에게 직관적이고 창의적인 사고의 관점을 제공하는 계기가 될 것이다.

\section{참고 문헌}

1. Henk J. M. Bos, Lectures in the History of Mathematics, Amer, Math. Soc., 1993.

2. Michael J. Crowe, A History of Vector Analysis, University of Notre Dame Press, 1967.

3. Jean-Luc Dorier, "A General Outline of the Genesis of Vector Space Theory", Historia Mathematica 22(1995), 227-261.

4. Jean-Luc Dorier, "Epistemological Analysis of the Genesis of the Theory of Vector Spaces", On the Teaching of Linear Algebra, Edited by Dorier, Kluwer Academic Publishers, 2000, 1-82.

5. H. Eves, Great Moments in Mathematics, 1978. 허민 외 역, ‘수학의 위대한 순간들」, 경문사.

6. Lewis \& Albert C. H., "Grassmann's 1844 Ausdehnungslehre and Schleiermacher's Dialektik”, Annals of Science 34(2) (1977), 103-162.

7. Albert C. Lewis, "The unity of logic, pedagogy and foundations in Grassmann's mathematical work", History and philosophy of logic 25(2004), 15-36.

8. Michael Otte, "The ideas of Hermann Grassmann in the Context of the Mathematical and Philosophical Tradition since Leibniz", Historia Mathematica 16(1989), 1-35.

9. Mircea Radu, “Justus Grassmann's Contributions to the Foundations of Mathematics: Mathematical and Philosophical Aspects”, Historia Mathematica 27(1) (2000), 4-35. 